\title{
Effectiveness of Education of Working Memory Strategies on Improvement of Reading Performance and Reduction of Depression in Children with Dyslexia
}

\author{
Abed Mahdavi \\ Corresponding Author. Psychology Department, Payame Noor University (PNU) \\ PO BOX 19395 - 3697, Tehran, Iran; Email: Abed_Mahdavi@yahoo.com
}

Mohammad Ehsan Taghizadeh

Psychology Department, Payame Noor University (PNU), PO BOX 19395 - 3697, Tehran, Iran

Soudabeh Isazadeh

Psychology Department, Payame Noor University (PNU), PO BOX 19395 - 3697, Tehran, Iran

Kheirollah Kazem Nia

Psychology Department, Payame Noor University (PNU), PO BOX 19395 - 3697, Tehran, Iran

Shahryar Vojdani

Psychology Department, Payame Noor University (PNU), PO BOX 19395 - 3697, Tehran, Iran

Seyedeh Nafiseh Hosseini

Psychology Department, Payame Noor University (PNU), PO BOX 19395 - 3697, Tehran, Iran

Maryam Falahati

Psychology Department, Payame Noor University (PNU), PO BOX 19395 - 3697, Tehran, Iran

\section{Doi:10.5901/mjss.2015.v6n6s6p66}

\section{Abstract}

The present investigation was aimed to study the impact of education of working memory strategies on improvement of reading performance and reduction of depression in third grade elementary school students with dyslexia in Kouhdasht city. For this reason, after running the diagnostic test, 33 students were chosen among third grade elementary school dyslexic students with depression disorder through random cluster sampling method. Afterwards, they were placed in experimental and control groups randomly. The participants in the experimental group received training in strategies for working memory in 15 sessions. Eventually, the obtained data were analyzed using statistical covariance analysis. The results demonstrated that the reading performance of students in the experimental group significantly improved compared to the control group. Moreover, depression level significantly decreased compared to the control group.

Keywords: strategies for working memory, dyslexia, depression and performance improvement

\section{Introduction}

Reading is the most fundamental learning tools for students (Sen, 2009). Reading is a psychological-linguistic process based on information on vision, knowledge of the reader and phonological and semantic rules. In fact, reading is a result of cognitive abilities, language, prior knowledge and skill acquisition in specific reading abilities (Allah Radi, Modaresi and Mohammadi, 2001). Dyslexia is one of the most common learning disabilities. The International Dyslexia Association defined this disorder as a specific learning disability that has a neurodevelopmental and neurological basis. This defect has negative impact on the accuracy and speed of word recognition, spelling and development of a quick phoneme- 
character relationship (Ahmad Panah, Pakadania, 2007). Definition of dyslexia based on DSM IV:

A) The results obtained from assessment of obvious reading abilities is less than the level expected with respect to chronological age, intellectual class and training appropriate to the age of the participants.

B) Disturbance described in part A significantly coincides with academic achievement or activities of daily living, which demands reading capacity.

C) If there is a sensory impairment, then reading problems are mostly beyond problems accompanied with this impairment (Sadock and Sadock, 2007).

Dyslexia exists in about $75 \%$ of children and teenager with learning disability (Omidvar, 2005). The age of onset and prediction of dyslexia should be at least 2 years less than chronological or educational age, so its recognition is not possible before 8 years old (Dadsetan, 2000). Specifically, dyslexia is a kind of disorder in confusion of similar words, guessing words with regard to the letters of the beginning and ending of the word, mirror reading or inversion reading of words, extreme difficulty in spelling words, aversion to learning to read and difficulty in identifying components of the total (Brooks, Berninger and Abbott, 2011).

Almost $80 \%$ of the students with learning disability face with problem in reading (Wallace, 2008; Mayes and Calhoun, 2006). Swanson, Harris and Graham (2003) reported about $12 \%$ of the second grade primary school students as the highest prevalence rate of reading disorder and about $15 \%$ of the fifth grade primary school students as the lowest prevalence rate. Zahed (2012) demonstrated in an investigation that there is a significant difference between students with dyslexia and normal students in terms of working memory. Working memory is responsible for temporary storage of information for cognitive processing. Some of the related conducted researches indicated that people with dyslexia have weaker skills in verbal working memory than visual-spatial working memory (Jenifer and Edward, 2004; Swanson, Howard and Saez, 2006). Bakhshi and Pirzadi (2012) demonstrated that thinking-based and self-supervision active metacognition strategies have positive features. Moreover, their application leads to enhancement of reading comprehension and reading skills of students. Kirk and Chalfont (1988; quoted from Bahari and Seif Naraghi, 2008) classified reading errors in students as the following. 1) Elimination: the child eliminates some of the words or parts of them in a sentence. 2) Increasing: the child puts some additional words in a sentence. 3) Substituting: the child substitutes a word with another word. 4) Repetition: the child repeats some of the words during reading. 5) Removing and adding. 6) Inversion: the child reads "wind" as "widn". 7) Reading rapidly and without accuracy or slowly and word by word. Most of the researchers found that students with reading disability experience more depression compared to their peers although the related rate was between 14\% and 36\% (Rodriguez and Routh, 2006). Similarly, it has been demonstrated that children who referred to outpatient mental health center had higher rates of disability (Cantwell and Barker, 2003). Children with learning disability might experience more severe depression than older children with learning disability experience, because older children understand their disabilities increasingly and deal them more easily (Miller and Kelley, 2001). There are so many reasons about why children with learning disabilities might experience depression. Some of the children might be able to tolerate repeated failures and setbacks as a result of their learning disabilities (Grolinck and Ryan, 2001). Lack of consideration of disappointment and its reasons might lead to development of feelings such as helplessness, inadequacy and frustration (Agran et al., 2005). Therefore, negative consequences resulting from the existence of dyslexia and associated academic failure can lead to emotional disorders such as depression, so the mentioned issue should be under special consideration (Yaghoubi and Ahadi, 2004). According to what has been mentioned, the present investigation is to aimed study the impact of education of working memory strategies on improvement of reading performance and reduction of depression in third grade elementary school students with dyslexia in Kouhdasht city.

\section{Research Hypotheses}

- Education of working memory strategies leads to improvement of reading performance of dyslexic students.

- Education of working memory strategies leads to reduction of depression of dyslexic students.

\section{Methodology}

The investigation method is quasi experimental with post-test and pre-test with control group. The population consisted of all third grade elementary school students with dyslexia in Kouhdasht city in the academic year of 2013-2014. Selection of the participants and their substitution in control and experimental groups was randomly. Thirty-two individuals were chosen from the children after implementation of reading disability test and Wechsler intelligence scale for fourth edition children and obtaining parents and students' consent for taking part in the research, and they were divided into two 
groups of 15 individuals (15 individuals in the experimental group and 15 individuals in control group). Afterwards, 15 sessions were designed and implemented in 3 months according to Den's educational program (2008). Each session was held in 1 hour and 3 times in a week. The obtained data was analyzed using covariance analysis.

\subsection{Working Memory Training sessions are summarized as follows:}

First session (introducing the method): the role of working memory in performing tasks related to reading is mentioned.

Second session (auditory memory): consisted of training of activities related to fulfilling orders, tracking orders, memorizing some simple words, memorizing short poems for children.

Third session (visual memory): consisted of hiding an object, identifying eliminated objects, recalling observed objects, recalling faces, repetition of patterns and model.

Fourth session (auditory and visual memory practices): auditory and visual memory practices are repeated again and the child performs additional practices either.

Fifth session (playing with picture): some pictures are shown to the child and then, it is asked to recall the colors and directions after 15 seconds.

Sixth session (fulfillment of orders): some simultaneous orders are given to the child and he should perform them precisely.

Seventh session (showing movie): some short movies are shown to the child. After finishing the movie, the child does the behaviors by recalling and rebuilding the same patterns.

Eighth session (recognition memory): pictures of children, animals, fruits and objects are shown to the children and they should identify them after a few seconds.

Ninth session (recalling memory): stories are read for the children in a few minutes (maximum three minutes) and the child should restate them.

Tenth session (long-term memory): children are asked to recall events happened in 24 hours before in detail.

Eleventh session (list of learning): children are asked to memorize a list of words prepared before and remember them. Moreover, they should restate the sentences presented in the classroom by the trainer.

Twelfth session (practice): an overview of the contents of the previous session and playing with cards and words and recognition of presented words among a set of cards (the session is aimed to strengthen data maintenance in the absence of assignments).

Thirteenth session (rehearsal techniques): training rehearsal techniques (frequent reading and frequent writing).

Fourteenth session (rehearsal techniques): continue of training rehearsal techniques (frequent reading and frequent writing).

Fifteenth session (practice): an overview of the contents of the previous session and continue of training rehearsal techniques.

\section{Research Instruments}

Wechsler Intelligence Scale for Children Revised- Fourth Edition (WISC-IV): the scale is the revised form of the third edition (1991) developed by Wechsler for children between the age of 6 and 16 in 2003. Wechsler intelligence scale (4th edition) provides four scale scores including verbal comprehension, perceptual reasoning, working memory and processing speed. The scale was normalized by Abedi (2008) for an Iranian sample. The validity of the subscales was between 0.65 and 0.95 and split-half reliability coefficients were reported between 0.71 and 0.86 . Wechsler Intelligence Scale for Children (4th edition) was employed in the present investigation in order to evaluate intelligence and working memory in the two groups.

Reading disorder test: in order to recognize dyslexic students, we used reading disorder test of Nesfat et al. (2001). Based on the test, three major clinical features including reading errors (eliminating, adding, moving, altering and reverse reading), reading speed and reading comprehension of students with dyslexia were evaluated. In addition, a score was assigned to each of the errors and the summation is considered as the total error of the participants. A score is also considered for answering to each of the questions in reading comprehension. Eventually, the time the participants spent from beginning to end of the test (in second) is the reading speed. The reliability and validity are 0.92 and 0.76 , respectively. 
Table 1. Results of covariance analysis of reading performance of the third grade high school students in pre-test and post-test

\begin{tabular}{ccccccl}
\hline Test power & Sig. level & $\mathbf{F}$ & Mean of squares & DOF & Sum of squares & Resources \\
\hline 0.81 & 0.001 & 11.14 & 36.51 & 1 & 36.65 & Pre-test \\
0.88 & 0.001 & 75.10 & 11.95 & 1 & 11.77 & Group \\
& & & 25.32 & 29 & 25.89 & Error \\
& & & & 31 & 80.22 & Total \\
\hline
\end{tabular}

The results demonstrated that there was no significant difference between the mean of reading test scores of students before presenting the independent variable (training working memory) but there was significant difference between the scores after presenting the independent variable.

Table 2. Results of covariance analysis of reading performance of the third grade high school students after 4 month

\begin{tabular}{ccccccl}
\hline Test power & Sig. level & $\mathbf{F}$ & Mean of squares & DOF & Sum of squares & Resources \\
\hline 0.74 & 0.4 & 0.26 & 0.02 & 1 & 0.02 & Pre-test \\
0.96 & 0.001 & 230.42 & 14.91 & 1 & 15.02 & Group \\
& & & 0.07 & 29 & 1.68 & Error \\
& & & & 31 & 16.47 & Total \\
\hline
\end{tabular}

As it demonstrated in table 2, there was significant difference between the control group and experimental group, therefore, it can be stated that students' performance improved through the impact of training working memory and this improvement was significant.

Table 3. Results of covariance analysis of depression of the third grade high school students in pre-test and post-test

\begin{tabular}{ccccccl}
\hline Test power & Sig. level & $\mathbf{F}$ & Mean of squares & DOF & Sum of squares & Resources \\
\hline 0.91 & 0.003 & 1.26 & 11.18 & 1 & 10.39 & Pre-test \\
0.85 & 0.0001 & 230.42 & 69.95 & 1 & 69.45 & Group \\
& & & 0.89 & 29 & 26.13 & Error \\
& & & & 31 & 120.85 & Total \\
\hline
\end{tabular}

According to the previous table, the scores are significant in pre-test and post-test, so the research hypothesis based on that reading performance improvement leads to reduction of depression in students is approved.

Table 4. Results of covariance analysis of depression of the third grade high school students after 4 month

\begin{tabular}{ccccccl}
\hline Test power & Sig. level & $\mathbf{F}$ & Mean of squares & DOF & Sum of squares & Resources \\
\hline 0.88 & 0.18 & 1.84 & 2.79 & 1 & 2.65 & Pre-test \\
0.86 & 0.0001 & 17.55 & 24.98 & 1 & 24.35 & Group \\
& & & 1.44 & 29 & 40.09 & Error \\
& & & & 31 & 71.25 & Total \\
\hline
\end{tabular}

According to table 4 , it can be concluded that the results were stable after 4 month and there was a significant relationship between the two groups in the amount of reduction of depression.

\section{Conclusion}

The purpose of the present investigation was studying the effectiveness of teaching working memory on reading performance improvement and reduction of depression in students with dyslexia. The findings demonstrated that learning working memory strategies has significant impact on reading performance improvement and reduction in symptoms of depression. Since students with dyslexia experience a higher rate of depressive disorder compared to healthy students, reduction in depression was expected with the improvement of reading performance of dyslexic students, which the result was the same and in line with other related investigations. 
The other investigations indicate that the capacity of the memory could be extended after education and learning. Interventions for working memory are based on teaching strategies related to the memory (Olson et al., 2004). Mir Mahdi et al. (2009) studied the impact of teaching executional functions including working memory in children with disability in reading and mathematics. The results demonstrated that their performance improved after finishing the course and following-up. According to the results, it can be concluded that teaching strategies related to working memory can reduce problems associated with dyslexic students and symptoms of depression. On other words, children should have mastery over a set of skills in order to have mastery over reading assignments. These skills are cognitive-neural aspects such as working memory and consideration. Acquisition of these skills is possible through experience, education and learning. Most of the children perform such skills automatically, but children with dyslexia learn these skills difficultly and they should be taught. Teaching such skills leads to strengthening visual-spatial, verbal and ... working memory and also leads to improvement and enhancement of learning performance in students. Therefore, teaching working memory leads to improvement of reading problems, especially in the field of reading comprehension.

Identification of problems students with reading disabilities deal with in cognitive-neural aspects including working memory can help the department of education to realize the problem and design appropriate education plan. According to the impact of teaching working memory strategies on improvement of reading performance and reduction of symptoms of depression in students with reading disability, it can be concluded that paying attention to working memory could be effective in treatment of learning disability like infrastructure skill of reading.

\section{References}

Abedi, M.R. (2008). Adaptation and standardization of Wechsler intelligence scale for children, fourth edition (WISC-IV). Isfahan: Neveshte Publication.

Nesfat, M. (2001). Reading disorder diagnosis test. Tehran: Tehran University Publication.

Ghobari Bonab, B., Afrouz, Gh.A., Hasanzadeh, H., Bakhshi, J. and Pirzadi, H. (2012). The impact of education of thinking-based and self-supervision active metacognition strategies on perception of students with reading disorder.

Allah Radi, M., Modaresi, L. and Mohammadi, E. (2001). Study and comparison of visual perceptions, auditory and visual and sequencing memory and phonological awareness skills in children with dyslexia and normal children. Bachelor of Arts thesis in Speech Therapy. University of Welfare and Rehabilitation Sciences.

Ahmad Panah, M. and Pakadania, P. (2007). A review of recent researches. Research on Exceptional Children, 7(3). 237-252.

Sadock, B., Sadock, V. (2007). Synopsis of Psychiatry of Kaplan and Sadock (Translated by Pour Afkari, N.A., 2009). Vo. 3, Tehran: Shahr Aab Publication.

Omidvar, A. (2005). Spotlight impairment in learning. Mashhad: Sokhan Gostar Publication.

Ghomri Givi, H., Narimani, M., Mahmoudi, H. (2012). Effectiveness of cognitive advancement software on executive functions, response inhibition and working memory in dyslexic children with hyperactivity disorder/ attention deficit, 1(2), 98-110.

Dadsetan, P. (2000). Diagnostic and rehabilitation methods impairments. Tehran: SAMT Publication.

Bahari Ghare Goz, A. and Seif Naraghi, M. (2008). Effectiveness of Sina educational instrument in reduction of mistakes and errors in children with dyslexia. Journal of Iranian Psychologists, 4(16). 91-102.

Mehr Mahdi, R., Alizadeh, H., Seif Naraghi, M. (2009). Impact of training of executive function on mathematics' performance and reading in elementary school students with learning disabilities, Research on Exceptional Children, (1): 1-12.

Yaghoubi, A. and Ahadi, H. (2004). Impact of training of metacognitive strategies on improvement of reading performance in fourth and fifth grade primary school male students with dyslexia in Hamadan city. Journal of Faculty of Education and Psychology, Al-Zahra University, Vol. 1, No. 1, pp. 47-57.

Sen, H. S. (2009). The relationsip between the use of metacognitive strategies and reading comprehension. Procedia Social and Behavioral Sciences, 1(15), 2301-2305.

Swanson, H. L., Howard, C. B., \& Saez, L. (2006). Do different components of working memory underlie different subgroups of reading disabilities? Journal of Learning Disabilities, 39(3), 252-269.

Jeffries, S., \& Everatt, J. (2004). Working memory: its role in dyslexia and other specific learning difficulties. Dyslexia, 10(3), 196-214.

Dehn MJ. Working memory and academic learning. New Jersey: Wiley; 2008. Olesen PJ, Westerberg H, Klingberg T. Increased prefrontal and parietal activity after training of working memory. Nature Neuroscience. 2004; (7): 75-79.

Swanson, L. H., Harris, R. K., \& Graham, S. (2003). Handbook of learning disabilities. New York, NY: Guilford Press.

Wallace, A. J. (2005). Early identification of learning disorders helps children succeed. Pediatr Ann, 34(4), 328-329.

Mayes, S. D., \& Calhoun, S. L. (2006). Frequency of reading, math, and writing disabilities in children with clinical disorders. Learning and Individual Differences, 16(2), 145-157.

Brooks, A. D., Berninger, V. W., \& Abbott, R. D. (2011). Letter naming and letter writing reversals in children with dyslexia: Momentary inefficiency in the phonological and orthographic loops of working memory. Developmental Neuropsychology, 36(7), 847-868.

Rodriguez, C.M., \& Routh, D.K. (2006). Depression, anxiety, and performance experience of learning disabled and non-learning disabled children. Journal of clinical child psychology, 18, 299-304.

Cantwell, D. P., \& Baker, L (2003). Association between attention-deficit hyperactivity disorder and learning disorders. Journal of 
learning disorders. 24, 88-95.

Miller, D.L.., \& Kelley, M.L. (1994). The use of goal setting and contingency contracting for improving children's homework: Journal of Applied Behavior Analysis, 27, 73- 84.

Grolinck, W.S., \& Ryan, R.M. (1990). Self-perceptions, motivation and adjustment in children with learning disorders: A multiple group comparison study. Journal of learning disorders, 23, 177-184.

Agran, M., Salzberg, C.L. and Stowitstchek, J.J. (2005): An analysis the effects of social skills program using self- instruction on the acquisition and generalization of two social behaviors in a work setting. Journal of the association for persons with severe handicaps, 12,131- 139 . 